Barbara M. Jones

\title{
HIDDEN COLLECTIONS, SCHOLARLY BARRIERS: CREATING ACCESS TO UNPROCESSED SPECIAL COLLECTIONS MATERIALS IN AMERICA'S RESEARCH LIBRARIES ${ }^{1}$
}

\begin{abstract}
Many people contributed to this paper, including: Nicole Bouche, Head of the Manuscript Unit, Beinecke Library, Yale University; Pat Bozeman, Head of Special Collections and Archives, University of Houston Libraries; L. Gayle Cooper, Special Collections Cataloger, Albert \& Shirley Small Special Collections Library, University of Virginia; David Faulds, Special Collections Cataloger, General Libraries, Emory University; Jain Fletcher, Head, Technical Services Division, Department of Special Collections, Research Library, University of California at Los Angeles (UCLA); Jane Gillis, Rare Book Cataloger, Sterling Memorial Library, Yale University; Julie Grob, Special Collections Librarian, University of Houston Library; Tom Hyry, Archivist, Sterling Memorial Library, Yale University; Deborah J. Leslie, Head of Cataloging, Folger Shakespeare Library; Elizabeth Lilker, Cataloger, New York University Libraries; George Miles, Curator, Western Americana Collection, Beinecke Library, Yale University; Christopher Prom, Assistant Professor and Assistant University Archivist, University of Illinois Library at Urbana-Champaign; Henry Raine, Project Manager, NYU-YHS Mellon Project, New York University Libraries; E. C. Schroeder, Assistant Head of Technical Services, Beinecke Library, Yale University; Suzy Taraba, Head of Special Collections and University Archivist, Olin Memorial Library, Wesleyan University; Katherine M. Wisser, Libraries Fellow, North Carolina State University. I gratefully thank the group of experts listed above, who wrote more than fifty pages of comments for this effort. Broken into four groups, they deliberated electronically for several weeks. They looked over the draft at least twice and offered comments. Although some is appended, there is much additional valuable information that didn't fit into the white paper but that should be published at some point. I also thank the members of the ARL Special Collections Task Force, who provided the support I needed to start the ball rolling.
\end{abstract}

\section{Hidden Collections and the Challenge They Present}

From the beginning of the ARL Special Collections Task Force's work in 2001 , it was clear that large unprocessed or underprocessed backlogs of rare book, manuscript, and archival materials were a major problem in research libraries around the country. Many participants at the Brown University ARL Conference on Special Collections in the summer of 2001 consistently listed materials backlogs as one of their institution's major concerns.

1. This white paper for the Association of Research Libraries Task Force on Special Collections was released on November 1, 2002. 
- Uncataloged or underprocessed collections are at a greater risk of being lost or stolen and are difficult, if not impossible, to recover from legal authorities if they are underdocumented. Unique and rare materials are particularly vulnerable.

- They are inaccessible to the scholarly community and thus hinder research and research results. Even when unprocessed collections are made available (which is a security risk), they are difficult, if not impossible, for researchers to locate unless they happen to suspect that the institution in question might have such a collection.

- Undergraduates, graduate students, and junior faculty, many of whom lack the financial wherewithal to travel to other institutions, are particularly affected by the lack of access to unprocessed collections in their own institutions.

- Access to unprocessed collections is staff dependent, to the detriment of the institution and the patron. Long-time staff become the source of expertise for these collections; when they move on or retire, that undocumented "institutional memory" is lost.

- Unprocessed collections are totally inaccessible because they are likely to be in closed stacks, eliminating the possibility of discovery by browsing.

- Often special collections have been excluded from general library retrospective conversion projects because of their perceived "exceptional" nature. When they have been included, in many cases the access points are misleading or even erroneous.

- Often materials have manual finding aids that can be used only in the repository-pencil markings in one set of books, a faded typewritten finding aid, etc. Even in that repository, nonstandard guides and noncurrent card catalogs are likely to be underutilized or even unknown to researchers.

- Unprocessed collections often result in purchasing duplicates already owned. 
- Poor donor relations can result from not making collections available in a timely fashion.

- In at least one public university, state auditors became concerned that books purchased with state funds were inaccessible to the public for years after purchase.

- Unprocessed collections often are lost and forgotten in storage areas and sustain physical damage from unstable temperature and humidity, or become worn from too much handling due to lack of finding aids.

\section{A. The Extent of the Problem of Special Collections Backlogs}

The 1998 survey of ARL special collections libraries illustrated this problem quantitatively. Libraries are simply unable to keep up with the backlogs, especially for those materials in nontraditional formats:

For example, for printed volumes, about 15 percent of collections on average remained unprocessed or uncataloged. For microforms-another format with well-established cataloging conventions and a frequently more formalized acquisition structure-the mean level of uncataloged materials was 13 percent.

Among 82 institutions reporting on manuscript collections, however, the mean for unprocessed portions of the collection rises to 27 percent, and a similar level (31 percent) was reported by 71 institutions for their university archives. Percentages of unprocessed materials continue to rise for video (35 percent), graphic (36 percent) and audio (37 percent) materials. The highest average for unprocessed materials (46 percent) was, perhaps not surprisingly, in the artifacts category. ${ }^{2}$

\section{B. Defining Access}

For purposes of this report, the term access refers to a means of discovery-through such surrogates as descriptive metadata, word of mouth, and references in the literature-that a particular body of information exists. This is coupled with the means of looking at the materials either directly or virtually. Access encompasses the processes followed to make

2. Judith Panitch, Special Collections in ARL Libraries (Washington, D.C.:ARL, 2000), 49-50. 
materials of all formats available to users, the tools used to publicize materials to potential users, and the openness with which we allow our collections to be used by the public.

The ARL Task Force on Special Collections determined early in its deliberations that access is crucially tied to service and needs to be electronic, especially because of the global nature of our services. Special collections materials need to be integrated into the information access protocols of their institution as a whole; finding aids, for example, should be part of the online public access catalog (OPAC) and available on the Internet. In the electronic environment, the pace of scholarly research in special collections has increased considerably. Cross-institutional research without electronic access is extremely time-consuming and frustrating for both researchers and librarians.

Increasingly, materials that are inaccessible electronically are simply not used.

\section{The Purpose of This Paper}

This white paper has been developed by a nationwide group of special collections professionals who are leaders in the special collections library community, including participants in the ALA's Rare Book and Manuscripts Section (RBMS) and the Society of American Archivists (SAA). Its purpose is to provide helpful background for university library directors, funding agencies, and other decision makers who want a current, concise statement of the problem of unprocessed special collections backlogs in research libraries around the country. We believe that a problem this large and complex, and shared by most ARL institutions, can best be addressed collaboratively at the national level as a special project. Current cataloging rules and practices for cataloging or arranging and describing materials must be examined for streamlining. Though this issue needs further discussion, most believe that it is better to provide some level of access to all materials than to provide comprehensive access to some materials and no access at all to others. In addition to traditional OPAC capabilities, it is important that we take advantage of the increased opportunities provided by markup languages and encoding structures such as Encoded Archival Description (EAD), databases, and digital projects for addressing this task.

Now is an especially good time to undertake this project. 
The timing is good because of concurrent activities to revise the cataloging rules for rare books and manuscripts. The Yale University Libraries/Beinecke Rare Books and Manuscripts Library will host a DCRM (Descriptive Cataloging for Rare Materials) revision conference in March, 2003. Revisions will incorporate guidelines for a standardized "collectionlevel record" and for some of the nontraditional formats that are frequently backlogged. In addition, the ARL Working Group on Access plans to host an invitational conference to discuss this white paper. The results of the two conferences should build a foundation of expertise and energy to move forward with a plan to help define twenty-first-century access to special collections and to seek funding for creating access to the backlogs.

This report addresses the following questions:

- What does "access" to special collections mean in the twenty-first century? How does access relate to service? What types of use and users do we want to encourage and facilitate with improved access, and how can we best achieve these goals? How can we best determine what researchers require for access to collections?

- What trade-offs are involved with the type and number of access points in a cataloging record or an archival finding aid? What are the most efficient ways to provide appropriate access to uncataloged and unprocessed materials? What are some of the absolutely essential components of archival, manuscript, and bibliographic records?

- How might the research library community collaborate to tackle these "hidden collections"? What level of staff is needed for various components? How can we share expertise? What might a work plan look like?

After this document has been circulated, the ARL Task Force on Special Collections plans to sponsor a two-day invitational conference at the Library of Congress, where scholars and leaders in the fields of rare books, archives, and manuscripts will discuss how this problem might be addressed collaboratively.

\section{Access: The Key to Excellent Service}

Addressing the backlogs of hidden collections is essential if we are to provide the services that a larger and increasingly diverse user popula- 
tion expect. Although special collections shares a number of important access issues with other library services, this paper focuses on those that are particularly problematic for rare book, manuscript, and archives researchers and the stewards of those collections.

\section{A. Increased Demand from a Diverse User Group for a Wider Variety of Services}

Once the sole provinces of faculty members and graduate students, special collections departments have expanded their mission in the digital age to serve a much broader group of patrons. Both an increase in proactive outreach activities, such as teaching, and the adoption of new technologies that make collections available through the Internet have led to special collections serving a very broad clientele. Instead of being "treasure rooms" open only to a few scholars bearing the proper credentials, special collections now are the places from which the cultural treasures of the library are disseminated into the community. Many special collections libraries now use direct marketing strategies to inform groups ranging from $\mathrm{K}-12$ students, community groups, undergraduates, distance learners, and television production units, to traditional research scholars, faculty, and graduate students. IMLS grants and other projects encouraging digital imaging have brought special collections into closer contact with such cultural organizations as museums and historical societies.

The twenty-first century has provided new challenges and opportunities for access, including the suspension of geographical and temporal boundaries through electronic representation of the contents and the artifacts within a collection, and a renewed concern of collaboration between special collections and their clientele. The processes have expanded to include arrangement and description through electronically accessible metadata encoding standards such as HTML Dublin Core and EAD. Special collections are working together consortially to create databases of searchable finding aids, such as the Online Archive of California, the Virginia Heritage Project, and the Texas Archival Resources Online, to improve researcher access to collections. In addition, the availability of digital surrogates of collection items has added a new digital dimension to access that requires a new set of processes for special collections librarians.

In fact, this new type of special collections service is best supported by electronic delivery of information. Each special collections library holds unique materials so that we have a special obligation and demand to deliver information remotely. The World Wide Web and other electronic 
resources have provided an extremely useful tool for service to patrons abroad, the physically disabled, and those who prefer to work at home. The Internet also has brought a world of new users to special collections. Genealogists are finding their ancestors' names within the pages of a finding aid. Military history buffs are finding documents from the regiment they are researching on a Web site. Writers wanting historical background for novels and screenplays and secondary school students writing reports contact special collections with reference requests.

Teaching is another important way that special collections librarians share their collections with their institutions and the general public. At university libraries, faculty members collaborate with special collections librarians on assignments that bring undergraduates in to work with primary research materials. Secondary school teachers consult with librarians to choose original materials that their students can look at and touch during class visits. Parents who are home-schooling bring their children in to get a firsthand look at history. And seniors visit the reading room as lifelong learners participating in Elderhostel and similar programs.

Special collections also reflect the unique identity of a particular library, as other units and collections become increasingly homogeneous. As universities recognize special collections as showcases of campus cultural life, visitors and prospective donors are increasingly asking for assurance that any gifts made to special collections libraries will be accessible to the public.

What does service look like in this new special collections environment? Without straightforward access to special collections materials, service is severely compromised, especially if it differs from service of "mainstream" library materials. Patrons may shy away or be discouraged from using special collections if there are too many complex barriers. Good service has to do with the ease and timeliness of delivering the special collections materials content the patron desires. There needs to be a pathway to the desired knowledge that is easy for the patron to use. The mediation of a professional special collections librarian will always be essential, but it must be designed to meet the needs of today's users of special collections. In the past, users were seasoned scholars who had identified a topic of study and knew the resources they were looking for. Today, special collections librarians are working increasingly with patrons who need help in conceptualizing projects and are using resources previously unknown to them. 
The various types of access, many originally created or customized within an individual special collections library, include the following:

- Finding aids

- Bibliographic records in MARC format, at various levels of complexity

- Catalogs

- Web pages

- Specialized bibliographies

- Exhibits

- Public readings, talks, and panel discussions

- Digital representations of artifacts and manuscripts

- Relational databases

- Subject guides

\section{B. Measuring Patron Access in This New Environment}

With the diverse types of access tools listed above, it is important that special collections librarians consider which tool will provide the most satisfactory patron access for a particular collection. This essential analysis mandates a balance between the ideal access record for "every patron" and economic realities. This important question of measuring access and services must be addressed by the planners of any collaborative project to process backlogs.

Determining what will best serve researchers in terms of access will always be a difficult challenge. There are several ways to approach this issue, each with accompanying repercussions. For instance, librarians can actively collect data, including interviews of faculty and students. However, this does not reach the new, nontraditional patron groups that are beginning to use our collections. We can, as well, rely on professional expertise, but that may be mired in "traditional" conceptions of how access is provided and not speak to patron needs.

Much research continues to be conducted on accessibility in other areas of librarianship on which special collections could rely to provide a data framework on which to expand and groundwork for further research needs. Many special collections libraries already collect data about their researchers, including how or where they found out about special collections. These data could be mined to see what kinds of gateways are being used most often. An assessment of what has been working (i.e., online catalog records, finding aids on the Web, word of mouth, refer- 
ences from another department, etc.) and who it has been working for will provide a baseline for further inquiries.

Although these techniques will not provide definitive answers to the questions of how to improve access to special collections, they will begin to address some of the need for information and feedback. Designers of a collaborative backlog processing project will need to decide early on how, and to what degree, to measure user access needs.

\section{How Much Access Is Enough Access? Factors to Consider}

The writing of this paper began with much weight placed on streamlining the cataloging rules as a major solution to the backlogs. It became clear early on that other equally important factors needed to be considered. Thus, the original question has broadened into a set of preliminary recommendations that begin with, but go far beyond, the revision of the cataloging rules. In analyzing the backlog in light of security and user needs, libraries must decide the level of access they can afford. There may well be different levels of access required for different types of collections in different institutions.

Librarians also must consider the impact of their local decision on the national library and archival community. A thoughtfully prepared collection-level record might well be used instead of itemized cataloging of a collection of pamphlets. On the other hand, if at least one library does individual-item cataloging, this record could be used by other libraries worldwide. A full-level cataloging record can be used by local scholars, but also by other catalogers for derivation. This is particularly valuable when one looks at the records done by the American Antiquarian Society and for various microform sets (e.g., Early English Newspapers). Rarely used materials might get less treatment than frequently used or more valuable materials. With manuscript and archival collections, for example, a small collection of letters of a Revolutionary War general might be processed down to the individual-item level, while the voluminous records of a local business might only be processed to the file folder level. But, if the "rarely used materials" were more fully processed, they might be used more. These are but some examples of the kinds of decisions being made by special collections librarians daily and will need to be addressed collaboratively before undertaking a project of national scope.

The drafters of this section of the white paper have documented their extensive deliberations in an appended file of trade-offs and technical 
information on the creation of various types and levels of cataloging records and finding aids for special collections.

\section{A. Printed/Published Materials}

For printed materials, the current cataloging options include DCRB (Descriptive Cataloging for Rare Books) with full, core, and minimal level records. For example, in discussing the value of an added entry for a particular printer, one contributor looked at the trade-offs: "Why we need this: printers (early works, private presses, etc.) are important and collected in libraries. This gives access to them easily in an authorized form. What is lost if we don't have it? [We] could only find printers using a keyword search and then would have to do many searches in the different forms printer appears in order to find one printer. Not as essential as other access points." The March 2003 DCRM (Descriptive Cataloging for Rare Materials) conference at Yale will revise the current cataloging rules. The conference's goal is not to abbreviate cataloging; three levels have been developed already and are being used. Rather, the group will add rules and practices for more types of materials - such as rules for nineteenth-century material and other "non-hand press works" - and make the current rules easier to follow. These measures will certainly help make the cataloging workflow more efficient.

Many catalogers are optimistic about the potentially time-saving collection-level record that will be standardized at the DCRM conference. The collection-level record entails a MARC record describing the overall collection and allows for itemization to be attached at the same or later date. This standardization of collection-level records is sorely needed. As one drafter commented, "Collection-level cataloging is potentially dangerous because if not done right, it will merely convert materials from 'unprocessed' to 'hidden.'" For example, one library reported that 95,000 nonitemized pamphlets are listed under one subject, "Pamphlets on the Great War," with no other guides or indexes. Another librarian provided a six-page account of her institution's massive project to create collection-level records, with the successes and failures, staffing levels, work flow, etc. (In fact, so many libraries reported problems with pamphlet collections that it appears, at least at this stage, that pamphlet processing might be a high priority for any collaborative processing project. It would be an ideal way to test the new rules for the collection-level record.) 


\section{B. Unique/Archival Materials}

Similar trade-offs exist in the arrangement and description of manuscript and archival collections. The challenge is somewhat different because the descriptive material for unique materials, unlike that for published material, must always be originally constructed by a cataloger at the institution holding the material. Thus, a great deal of professional time is spent on the "front end," that is, on the arrangement and description process. For every collection that exists in the manuscript librarian or archivist's backlog, decisions must be made about its priority in the processing work flow and to what level of detail the collection should be processed-the item, folder, or series level. For unique, archival material there are a number of standards: APPM, Best Practices Guidelines (RLG Best Practices and OAC Best Practices), and the series of SAA manuals.

EAD is a recently developed encoding structure based on Standardized Generalized Markup Language (SGMLA) and Extensible Markup Language (XML) that allows the contents of finding aids to be displayed hierarchically and searched across multiple finding aids held in various repositories. As libraries and archives form consortia, generally state based, to provide EAD-encoded finding aids to the public, they must first make decisions about how the finding aids will be organized and indexed for consistency and searchability. Old finding aids that are typed or handwritten must be put in electronic format, and finding aids based on unique institutional traditions must be standardized. The Online Archive of California provides an extensive and specific document of Best Practices Guidelines for institutions creating new finding aids to be included in the OAC database. Only through this level of standardization can finding aids be provided to researchers with fully searchable, cross-institutional access.

The initiatives described above have led to streamlining the processing of unique/archival collections, as collaborative EAD-based finding aid projects have encouraged the move from item level to folder or series-level finding aids. However, collections that are processed down to the item level enable researchers to access contents with pinpoint accuracy and to find topics that may not be the major focus of the collections. The tradeoffs with staff time are interesting in this case. In a department with limited staffing, the item-level finding aid makes it easier for a researcher to work independently. However, putting extensive staff time toward processing one collection means that others must go completely unpro- 
cessed. And an unprocessed or underprocessed collection poses a greater security risk and leads to more wear and tear on the paper as reference librarians shuffle through the collections to answer researchers' questions.

\section{Recommendations}

1. Consider various levels of cataloging and processing for all types of special collections materials, depending on institutional priorities and use of materials-but still following national standards and practices. Develop a decision-making criterion for the various levels and treatments. For example, How large is a group of similar items? Is the group large enough so that all the items are cataloged in a considerably shorter period of time than cataloging them individually? What is the collection's physical condition? Will the material be heavily used? Why is the item in special collections-Date? Provenance? Publication date? Subject? As several of the drafters suggested, institutions don't necessarily need new cataloging rules; rather, they need to be a lot more flexible about applying them and embracing the range of processing options.

2. Follow national standards and guidelines for all cataloging, arrangement, and description at the same time that individual libraries are making some local-level decisions. Planners must consider the impact of the transition from local, individual catalogs to virtual catalogs spanning multiple institutions.

Traditional cataloging rules and practices were geared toward making a coherent catalog from a single library's holdings. With individual institutional catalogs being increasingly "harvested" and combined into virtual catalogs spanning multiple institutions, practices that would formerly be decided on at an institutional level now need to be decided on a national level to achieve intellectual coherence in emerging, multiinstitutional agreements on descriptive cataloging rules and a shared set of metadata elements.

Because not all institutions are currently employing applicable national standards, the development of easy-to-use tools for file encoding and cataloging emerge as a priority. These tools should be simple enough to be used by students or paraprofessionals working under the supervision of librarians or archivists.

3. Strike a better balance between the resources committed to purchasing materials and accepting gifts and those resources committed to 
processing and cataloging them. Often gifts aren't factored into resource allocation. Some contributors questioned whether materials acquired as gifts that do not fit the collecting mission of the institution should be processed at all.

4. Weigh carefully the balance between the level selected to process a particular book or collection and the impact on public services staff. The University of Illinois Special Collections Curator has compiled statistics to show that the more levels he applies to processing manuscripts (electronically), the more reference questions his unit receives, but the less time the unit spends on answering each question.

5. Encourage interinstitutional collaboration. This should include regular meetings of special collections administrators, which could be another long-term positive outcome of this project. Currently, there is no formalized forum for special collections administrators. Collaboration could include sharing of various expertise, as is done in SALAM (Seminar on the Acquisition of Latin American Library Materials), which supports a cooperative cataloging program. Particular institutions focus on becoming as adept and efficient as possible in cataloging the publications of certain countries while relying on fellow members to develop similar skills for other countries. In special collections, many institutions already rely on the American Antiquarian Society's unparalleled expertise and interest in early American imprints to obtain extremely detailed catalog records for their own holdings. The records generated by this collaborative approach could increase the quality of the national bibliographic utilities and enhance scholarly searching, while at the same time providing high-quality copy cataloging for other members who will inevitably acquire material outside their areas of highest cataloging expertise.

Other suggestions to explore include the establishment of a single, national database with serial holdings of multiple institutions and a single, national database of acquisition records. A brief acquisitions record has been used by some special collections libraries as an interim substitute for nothing at all.

6. Develop different work flows for materials in various states of processing, for example, retrospective conversions records versus totally unprocessed materials. Records that are being transformed from one format to another - $\mathrm{a}$ brief record catalog card to a fuller online record, for example-have special considerations. Because this project assumes that 
access means electronic access, manual copies of cards and finding aids would be included as materials needing conversion.

Indeed, processing options need to include underprocessed materials in addition to those from old recon projects. It is important to consider a variety of solutions before automatically attempting yet another pass at conversion of text on cards. For example, one library holds the archives of a prolific poet. Many years ago, the manuscript of each poem was cataloged individually, while the rest of the archive was not processed. Today, faced with hundreds of cards to be converted, it might be better to ignore these cards and, instead, process the entire collection with a finding aid and a collection-level cataloging record.

Finally, the group developing the criteria for processing the backlogs should include in their mission an analysis of the reasons for the backlog in the first place. In addition to often-cumbersome and time-consuming cataloging rules and traditions for processing manuscript and archival collections, other problems include gifts acquired with no processing funds attached, out-of-scope materials that are difficult to dispose of, retrospective conversion of special collections as a low institutional priority, and low staffing levels for cataloging, arranging, and describing special collections materials. While planning a project to eliminate the backlogs, the group would do well to recommend a system for keeping up with newly acquired materials after the project is completed.

\section{Creating Access to Special Collections: A National Collaborative Project Approach}

We believe that there is an abundance of expertise in our research libraries-encompassing languages, subjects, cataloging, processing, and technology-to carry out a successful collaborative project to process the backlogs of hidden collections. Although the group would explore ways to use existing local resources to tackle some of this work, we do not think that this backlog can ever be absorbed into the routine work flow of any institution.

This group would work with two broad goals in mind. First, it would support the development of a uniform set of guidelines for a variety of cataloging and arrangement and description practices so that special collections can choose from a variety of access options but at the same time ensure the usability of interinstitutional virtual catalogs and online repositories of archival resources. Second, the group would examine 
ways to allocate efficiently the available cataloging and processing resources.

The ARL Special Collections Task Force could offer substantial advice and support in helping the group seek external funding to undertake this project, which might turn out to be a combination of local monies and foundation support for both planning and implementing the backlog processing.

The drafters of this paper offer this approach as one of many ways in which this project could be designed and implemented. We fully expect further discussions and refinement of this approach. In fact, at least one member of the group questions the efficiency of a collaborative project and wonders if, instead, grant funding targeted directly to particular institutions for projects might produce better results.

\section{A. A National Survey of Backlogs}

The drafters of this document first considered a follow-up to the 1998 ARL survey of special collections, sent to major research libraries, to precede the project design. The survey could be designed by a group of special collections librarians who could devise categories of types of backlogged materials to facilitate the compiling of responses from contributing libraries.

At their October, 2002 meeting, the ARL Special Collections Task Force advised not to burden the ARL membership at this time with another survey. Rather, the group would prefer to move ahead quickly toward holding a conference and seeking funding for processing the backlog. The group discussed the option of a pilot project; a group of perhaps five libraries could form a core group to survey their institutions and design the next steps accordingly.

Some of the categories of a survey might include "published" versus "unique" types of material (a-v, manuscript, book), language, date of publication, and status of processing (Is there any bibliographic record at all, or is the item truly uncataloged? Does a preliminary accession list exist for a collection, or is it an unknown jumble of boxes?) Institutions might be asked to prioritize ten collections for this project. At some institutions, this survey might necessitate an inventory or search of the backlog that would be time-consuming and argues for limiting the first steps to a pilot project and seeking a planning grant. The results would 
be used to design a workable proposal for funding the processing of the backlogs in a larger group of institutions.

\section{B. A Conference}

A two-day invitational conference would be held at the Library of Congress in the fall of 2003 to discuss this white paper and ways in which to proceed toward cataloging the backlogs. The conference would include scholars and professional practitioners of cataloging and archival processing, many who helped draft this paper and who have daily contact with the issues involved. Administrators who determine budgetary priorities, representatives from foundations, and other interested parties would be part of this deliberation. It also would include guest speakers from a variety of perspectives to encourage "out-of-the-box" thinking about these issues and incorporate innovations in software and metadata standards and practices.

The ARL Special Collections Task Force suggests that the planning group for the conference consider a subject approach as a way to analyze the backlogs. That is, two or three subject areas might be chosen for their breadth in formats, languages, preservation challenges, and dates. For example, if "infrastructure" was chosen as a subject, the conference attendees could consider materials ranging from railroad timetables to photos to pamphlets to the archival records of an airline, with a variety of formats, languages, and dates. This subject could be used as a model for designing a pilot project.

From this conference would emerge recommendations on how to tackle parts of the backlog and a group to seek funding. They would work closely with the conveners of the Yale conference on the revision of DCRM and other initiatives in the library and archives world.

\section{Seeking Funding}

A group of librarians, perhaps many of those who have been involved in developing this white paper and in organizing the two conferences, would be appointed by the ARL Special Collections Task Force to interpret the results of the conference and to translate them into a workable proposal or proposals for funding the project. They could categorize the materials, assign priorities, recommend levels of access and staffing, and set realistic goals and objectives. They would decide at this stage whether it is feasible to include any preservation data while preparing 
the collections or whether that would overly tax the project. It is understood and assumed that individual libraries would have discretion in deciding how to tailor this project to their library's goals and objectives, within a larger context of nationally developed criteria.

Next, the group would look at various ways to fund this processing. Options include:

- Pooling resources with other institutions in such areas as language and/or subject expertise

- Outsourcing some functions

- Creating a grant-funded project or projects with multiple institutions, sharing similar projects

- Funding large projects with multiple aspects from several sources

- Planning for long-term funding of ongoing technical services work

- Making adequate permanent staffing of technical services operations a priority for local funding

\section{Institutional Preparation for the Project}

Professional librarians and archivists will be needed for the initial planning, implementation, monitoring, and evaluation of this project. This will include selecting the collections of highest priority for the project and the work flow. They will determine which tasks can be allocated at various staffing levels, including regular and temporary staff, GAs, and student workers.

There must be recognition of the role of permanent library staff in designing and carrying out much of this project for purposes of quality control and understanding long-term implications and impact on local policies and practices. With this must be recognition of special collections backlogs and gifts as an integral part of library planning. Gifts, for example, need to be factored into available processing resources.

\section{Conclusion}

Although statistics show steady and dramatic growth in the use of special collections by diverse groups of users, the status of the backlogged hidden collections has not changed. Such hidden resources mean that scholarly projects may well be missing some crucial information that could affect research results and the very nature of the project. 
The ARL Special Collections Task Force has been focused on this problem for two years as one of the major problems in its member libraries. ARL can provide the leadership and lend its prestige in assisting a group of special collections librarians in acquiring funding to create access to these hidden collections.

A number of library and archival initiatives are taking place that will provide excellent experience and expertise for this project. The upcoming DCRM conference at Yale is but one example; others are listed in this paper. The fact that a key group of special collections professionals from all parts of the country have assembled to write this paper means there is now a group well acquainted with the issues and energized to tackle this project.

The cost to scholarship and society of having so much of our cultural record sitting on shelves, inaccessible to the public, represents an urgent need of the highest order to be addressed by ARL and other libraries.

The timing for undertaking this very important task couldn't be better. 